\title{
PECULIARITIES OF MICROSTRUCTURE AND IMPACT TOUGHNESS OF METAL OF WELDED JOINTS OF PIPES OF HIGH-STRENGTH STEEL WITH NIOBIUM AND MOLYBDENUM
}

\author{
A.A. RYBAKOV, T.N. FILIPCHUK and V.A. KOSTIN \\ E.O. Paton Electric Welding Institute, NASU \\ 11 Bozhenko Str., 03680, Kiev, Ukraine. E-mail: office@paton.kiev.ua
}

\begin{abstract}
The work describes the results of investigation of microstructure and impact toughness of metal of welded joints of gas-and-oil pipeline pipes of steel category X65-X80 with different content of niobium and molybdenum. Investigated were welded joints of longitudinal pipes of 820-1420 mm diameter with 17.5$36.0 \mathrm{~mm}$ wall thickness, manufactured by using the traditional technology with applying the double-sided submerged multiarc welding. Optical and electron scanning metallography, as well as standard impact bend tests were used. The negative effect of increased content of niobium on structural characteristics of metal of HAZ and weld was found, which was intensified in the presence of molybdenum. Taking into account the niobium susceptibility to segregation at the grain boundaries, the additional alloying with molybdenum, decreasing the temperature of transformation, leads to the formation of unfavorable structural constituents and phases in the metal of welded joints, and also their clustering along the grain boundaries, in particular in reheating regions. To provide high impact toughness and crack resistance of welded joints of pipes of high-strength microalloyed steel, it is necessary to limit in it, in addition to carbon, the content of niobium $( \pm 0.05 \%)$ and molybdenum $( \pm 0.20 \%)$, as well as to use the welding consumables, providing the mass share of molybdenum in weld of not more than $0.30 \%$. Results of the work were applied in industrial production of pipes of category X65-X80 at pipe welding enterprises of Ukraine and Russia. 8 Ref., 2 Tables, 6 Figures.
\end{abstract}

$\boldsymbol{K} \boldsymbol{e} \boldsymbol{y} \boldsymbol{w} \boldsymbol{o r d} \boldsymbol{s}:$ gas-and-oil pipeline pipes, microalloyed steel, welded joint, weld metal, heat-affected zone, microstructure, impact toughness

In construction of modern main gas-and-oil pipelines the pipes of strength class K60, K65 (category X65, X80) of microalloyed steel, produced by using the thermomechanical treatment, including controllable rolling and accelerated cooling, are mainly used. These steels contain, as a rule, $0.05-0.10 \% \mathrm{C}, 1.5-2.0 \% \mathrm{Mn}$ and elements increasing the austenite stability, such as $\mathrm{Ni}, \mathrm{Cr}$, Mo in the amount of up to $0.3 \%$ each. A complex microalloying with carbonitride-forming elements $(\mathrm{Ti}, \mathrm{V}, \mathrm{Nb})$, which total content usually is within $0.12-0.15 \%$, is also used [1-4]. The definite chemical composition of pipe steel, providing the required complex of properties, is determined by the applied technology of its production and technical characteristics of metallurgical and rolling equipment. For example, the limited potentiality of optimizing the cooling of strip after rolling is compensated by the higher alloying with carbide-forming elements and elements decreasing the temperature of $\gamma \rightarrow \alpha$ trans-

(c) A.A. RYBAKOV, T.N. FILIPCHUK and V.A. KOSTIN, 2015 formation. As a result, in steel of the same class of different producers the content of carbon and microalloying elements, first of all, niobium and molybdenum, can change within rather wide ranges reaching limiting values allowable by standards, in particular for steel K65.

It is generally accepted that the increase in level of alloying can lead to deterioration of steel weldability, in particular, the risk is increased for formation of regions with a lower toughness in welded joint metal and, as a consequence, the probability of brittle fracture developed in these regions is increased.

Some authors outline the negative effect of increased niobium content on the structural state and impact toughness of HAZ metal of welded joints of pipe steel, in particular, in zones of the repeated heating in multipass welding [5-7]. In our investigations the negative role of niobium increased significantly with increase in amount of molybdenum in steel. Results of these investigations are described in the present article. The data on structure and properties of weld metal of pipes of steel with increased molybdenum and niobium content are also given. 
Welded joints of longitudinal gas-and-oil pipeline pipes of $820-1420 \mathrm{~mm}$ diameter and $17.5-36.0 \mathrm{~mm}$ wall thickness, made of highstrength steel with different content of molybdenum and niobium, were investigated at a number of domestic and foreign pipe welding plants by traditional technology using a double-sided submerged multiarc welding [8]. The longitudinal welds of pipes were welded inside (internal weld, four-arc welding) and outside (external weld, five-arc welding) the pipe. The energy input of welding processes was within the ranges of $4-7 \mathrm{~kJ} / \mathrm{mm}$.

Content of main alloying elements and admixtures in steel for investigated pipes were in the following ranges, \%: $0.05-0.07 \mathrm{C}$; $0.242-$ $0.281 \mathrm{Si} ; 1.64-1.72 \mathrm{Mn} ; 0.13$ (in one melting -
$0.02)-0.22 \mathrm{Ni} ; 0.01-0,03 \mathrm{~V} ; 0.014-0.016 \mathrm{Ti}$; $0.027-0.035 \mathrm{Al} ; \mathrm{S} \leq 0.007 ; \mathrm{P} \leq 0.011$. Amount of $\mathrm{Nb}$ in steel changed from 0.040 up to 0.076 , and Mo changed from 0.01 up to $0.27 \%$. For comparison, the data on properties and structure of welded joint metal of pipe of steel of X65 category with minimum amount of $\mathrm{Nb}(0.017 \%)$ and almost absence of Mo $(<0.03 \%)$ are also considered.

The test pipes were given the conditional letter designations (Table 1). The base metal (BM) of pipes A and B represented steel of category X80 with increased content of molybdenum $(0.27$ and $0.18 \%$ ) and niobium ( 0.068 and $0.076 \%$ ). Total mass share of carbonitride-forming elements $(\mathrm{Nb}$, $\mathrm{V}$ and $\mathrm{Ti}$ ) in this metal was, respectively, 0.109 and $0.103 \%$. Steel of category X80, from which the pipe $\mathrm{C}$ was manufactured, refers to the same

Table 1. Typical chemical composition of base metal and metal of internal and external welds of investigated welded joints of pipes

\begin{tabular}{|c|c|c|c|c|c|c|c|}
\hline \multirow{2}{*}{$\begin{array}{l}\text { Conditional code of pipes } \\
\text { (category, thickness of BM) }\end{array}$} & \multirow{2}{*}{ Zone of inspection } & \multicolumn{6}{|c|}{ Elements, wt.\% } \\
\hline & & $\mathrm{C}$ & $\mathrm{Si}$ & $\mathrm{Mn}$ & $\mathrm{P}$ & $\mathrm{S}$ & $\mathrm{Ni}$ \\
\hline \multirow[t]{3}{*}{$\mathrm{A}(\mathrm{X} 80,22 \mathrm{~mm})$} & $\mathrm{BM}$ & 0.051 & 0.242 & 1.69 & 0.006 & 0.007 & 0.22 \\
\hline & Internal weld & 0.053 & 0.344 & 1.68 & 0.012 & 0.010 & 0.15 \\
\hline & External weld & 0.054 & 0.433 & 1.67 & 0.013 & 0.010 & 0.14 \\
\hline \multirow[t]{3}{*}{$\mathrm{B}(\mathrm{X} 80,17.5 \mathrm{~mm})$} & $\mathrm{BM}$ & 0.050 & 0.281 & 1.64 & 0.008 & 0.002 & 0.20 \\
\hline & Internal weld & 0.050 & 0.452 & 1.64 & 0.010 & 0.006 & 0.24 \\
\hline & External weld & 0.050 & 0.474 & 1.66 & 0.010 & 0.006 & 0.21 \\
\hline \multirow[t]{3}{*}{$\mathrm{C}(\mathrm{X} 80,27.7 \mathrm{~mm})$} & BM & 0.070 & 0.270 & 1.67 & 0.007 & 0.002 & 0.20 \\
\hline & Internal weld & 0.060 & 0.305 & 1.46 & 0.016 & 0.004 & 0.20 \\
\hline & External weld & 0.055 & 0.327 & 1.45 & 0.015 & 0.003 & 0.19 \\
\hline \multirow[t]{3}{*}{$\mathrm{D}(\mathrm{X} 65,36 \mathrm{~mm})$} & BM & 0.062 & 0.096 & 1.74 & 0.011 & 0.002 & 0.13 \\
\hline & Internal weld & 0.056 & 0.181 & 1.72 & 0.012 & 0.006 & 0.10 \\
\hline & External weld & 0.059 & 0.177 & 1.70 & 0.013 & 0.006 & 0.09 \\
\hline \multirow[t]{3}{*}{$\mathrm{E}(\mathrm{X} 80,17.5 \mathrm{~mm})$} & BM & 0.050 & 0.250 & 1.72 & 0.011 & 0.003 & 0.02 \\
\hline & Internal weld & 0.051 & 0.425 & 1.69 & 0.012 & 0.006 & 0.08 \\
\hline & External weld & 0.051 & 0.434 & 1.68 & 0.013 & 0.006 & 0.09 \\
\hline
\end{tabular}

Table 1 (cont.)

\begin{tabular}{|c|c|c|c|c|c|c|c|}
\hline \multirow{2}{*}{$\begin{array}{l}\text { Conditional code of pipes } \\
\text { (category, thickness of BM) }\end{array}$} & \multirow{2}{*}{ Zone of inspection } & \multicolumn{6}{|c|}{ Elements, wt.\% } \\
\hline & & Mo & $\mathrm{V}$ & $\mathrm{Ti}$ & $\mathrm{Nb}$ & $\mathrm{Al}$ & B \\
\hline \multirow[t]{3}{*}{$\mathrm{A}(\mathrm{X} 80,22 \mathrm{~mm})$} & $\mathrm{BM}$ & 0.27 & 0.030 & 0.014 & 0.068 & 0.027 & $\mathrm{~N} / \mathrm{D}$ \\
\hline & Internal weld & 0.35 & 0.029 & 0.016 & 0.045 & 0.020 & 0.0010 \\
\hline & External weld & 0.35 & 0.027 & 0.019 & 0.039 & 0.019 & 0.0013 \\
\hline \multirow[t]{3}{*}{$\mathrm{B}(\mathrm{X} 80,17.5 \mathrm{~mm})$} & $\mathrm{BM}$ & 0.18 & 0.012 & 0.015 & 0.076 & 0.035 & $\mathrm{~N} / \mathrm{D}$ \\
\hline & Internal weld & 0.28 & 0.008 & 0.014 & 0.043 & 0.023 & 0.0010 \\
\hline & External weld & 0.29 & 0.007 & 0.018 & 0.047 & 0.023 & 0.0015 \\
\hline \multirow[t]{3}{*}{$\mathrm{C}(\mathrm{X} 80,27.7 \mathrm{~mm})$} & $\mathrm{BM}$ & 0.15 & 0.020 & 0.014 & 0.045 & 0.036 & $\mathrm{~N} / \mathrm{D}$ \\
\hline & Internal weld & 0.25 & 0.019 & 0.019 & 0.022 & 0.022 & 0.0025 \\
\hline & External weld & 0.25 & 0.019 & 0.020 & 0.022 & 0.021 & 0.0030 \\
\hline \multirow[t]{3}{*}{$\mathrm{D}(\mathrm{X} 65,36 \mathrm{~mm})$} & $\mathrm{BM}$ & $<0.03$ & 0.020 & 0.015 & 0.017 & 0.031 & $\mathrm{~N} / \mathrm{D}$ \\
\hline & Internal weld & 0.05 & 0.020 & 0.018 & 0.011 & 0.017 & 0.0038 \\
\hline & External weld & 0.05 & 0.020 & 0.015 & 0.011 & 0.015 & 0.0040 \\
\hline \multirow[t]{3}{*}{$\mathrm{E}(\mathrm{X} 80,17.5 \mathrm{~mm})$} & $\mathrm{BM}$ & 0.01 & 0.010 & 0.016 & 0.040 & 0.027 & $\mathrm{~N} / \mathrm{D}$ \\
\hline & Internal weld & 0.10 & 0.006 & 0.013 & 0.021 & 0.018 & 0.0020 \\
\hline & External weld & 0.13 & 0.005 & 0.017 & 0.021 & 0.018 & 0.0028 \\
\hline
\end{tabular}


system of alloying ( $\mathrm{Mn}-\mathrm{Nb}-\mathrm{Mo}-\mathrm{V}-\mathrm{Ni}-\mathrm{Ti})$, however, it contains the lower amount of molybdenum and niobium $(0.15$ and $0.045 \%$, respectively), but here $\mathrm{Nb}+\mathrm{V}+\mathrm{Ti}=0.079 \%$. Pipes $\mathrm{D}$ and $\mathrm{E}$ are manufactured of steel of category X65 and X80 with minimum alloying: mass share of niobium was 0.017 and $0.040 \%$, there was no almost molybdenum, and $\mathrm{Nb}+\mathrm{V}+\mathrm{Ti}$ was equal to 0.052 and $0.066 \%$, respectively.

During investigations the impact toughness of metal was evaluated at negative temperatures on specimens with a sharp notch, made in different zones of the pipe welded joint. Structure of metal of welded joints was investigated by using optical microscopy, scanning electron microscopy and fractography.

It is known that in the HAZ of welded joints of high-strength pipes the zone of a coarse grain (ZCG) is most problematic, that is caused by a significant growth of austenite grain, formation of the coarse packets of plate-like ferrite and upper bainite, as well as the presence of MACphase, in particular of a lath morphology. It is considered that the minimum toughness is characterized by the zone of local embrittlement, formed due to reheating region of coarse grain of the first (internal) pass in welding of the second (external) pass, except of ZCG in HAZ, adjacent to the fusion line of internal and external longitudinal welds [5]. By this reason, when carrying out of metallographic examinations of HAZ the main attention was paid to structuralphase characteristics of metal of these regions in particular.

In metal of investigated welded joints of pipes at the ZCG of HAZ of internal and external welds a microstructure of the same type is formed, represented mainly by rather coarse packets of the bainite type structure: it is the ferrite with an ordered second phase of the lath morphology (Figure 1). The regions with the ordered and disordered second phase of granulated morphology are also observed. The formation of polygonal hypoeutectic ferrite along the boundaries of the former austenite grain in welded joint metal of investigated pipes was completely suppressed, with the exception of pipes $\mathrm{D}$ and $\mathrm{E}$ with minimum content of molybdenum and niobium, where the boundary precipitation of this structural component was found (Figure 1,c). Value of grains in HAZ metal, adjacent directly to the fusion line of external and internal welds, inde-

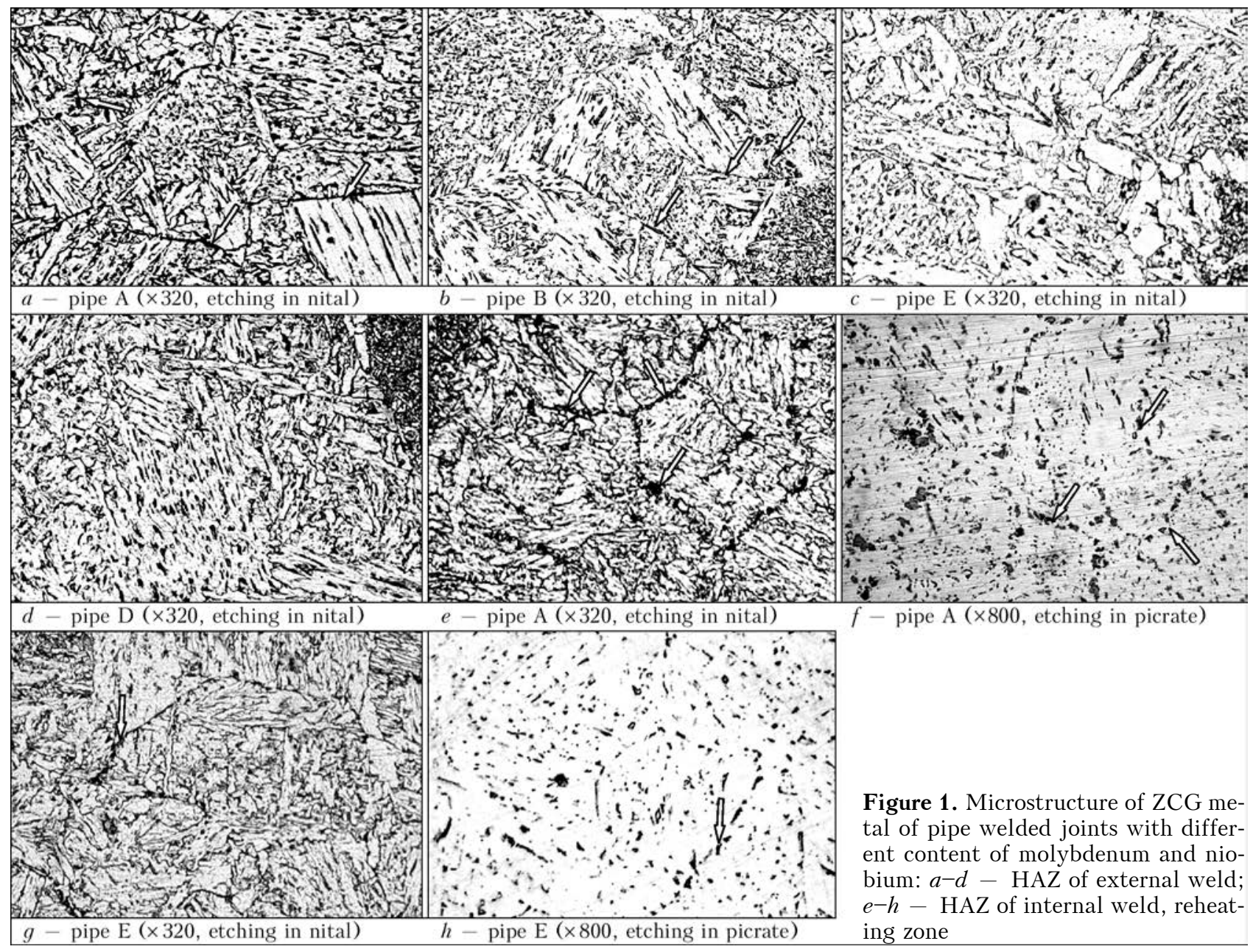




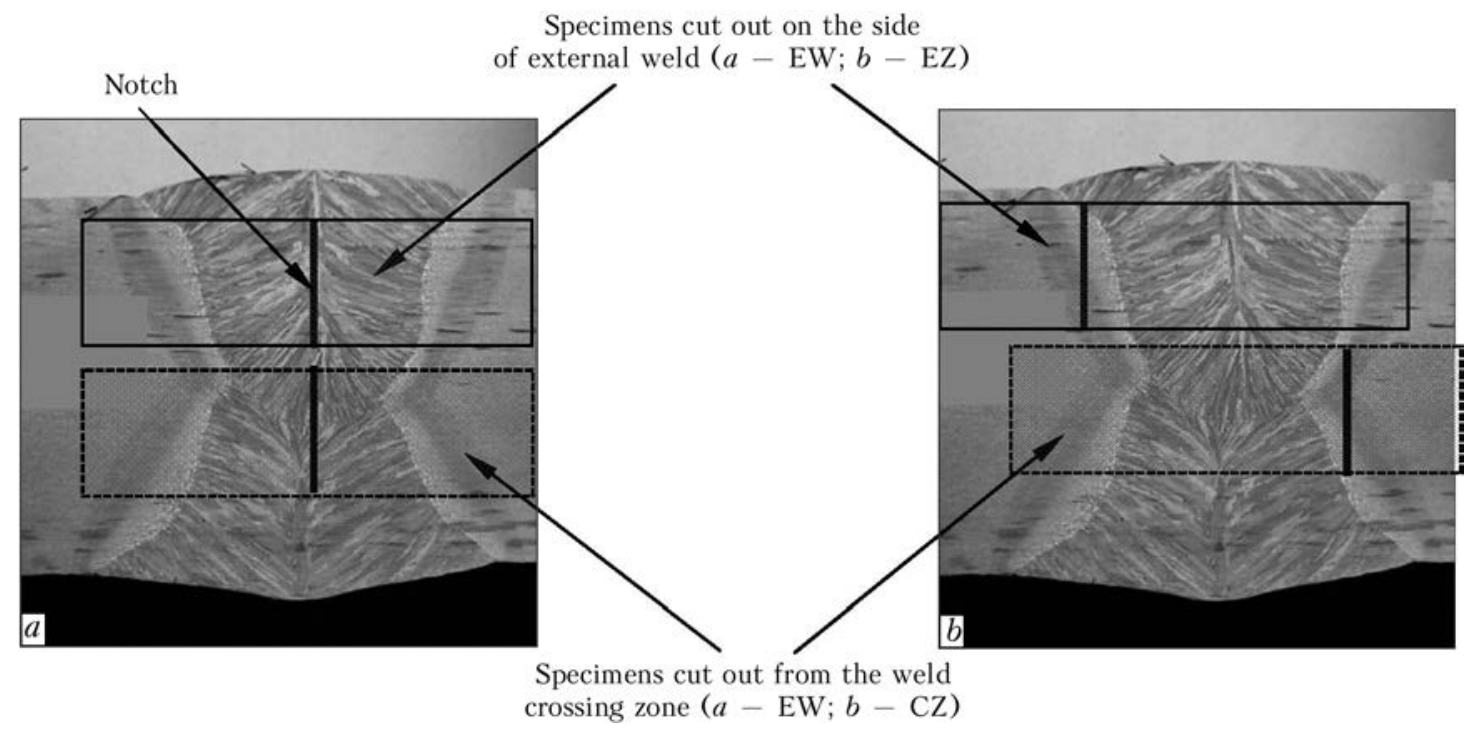

Figure 2. Scheme of cutting out of specimens and making a notch at impact bent test of weld $(a)$ and HAZ (b) metal

pendently of changing the mass share of molybdenum and niobium in the investigated limits, amount mainly to $54-108 \mu \mathrm{m}$, that corresponds to number 5-4 (by GOST 5639). Single larger grains of number 3 (of sizes up to $137 \mu \mathrm{m}$ ), revealed mainly in the fusion zone of external welds (in their apex), were also found, moreover, the large grains, as a rule, were fragmented into the finer subgrains.

As is seen from Figure 1, with increase in amount of niobium and molybdenum in steel (pipes A and B) the share of regions of brittle structure with similar oriented carbon phase (MAC-phase) of the lath morphology, as well as sizes (length and width) of precipitates of this phase are increased. The increase in the mass share of the mentioned elements in steel has the more negative effect on the state of boundaries of the metal grains in the examined zone. Thus, in metal of ZCG of external weld of pipes A and $B$ with high content of niobium and molybdenum, unlike the other examined welded joints of pipes, the carbon formations, such as MACphases and carbides, are precipitated intensively along the boundaries of the former austenite grain (shown by arrows in Figure 1, $a, b$ ). In metal of ZCG of internal welds in regions, subjected to repeated heating in making the external weld, the mentioned grain-boundary carbon precipitation was observed almost in all the examined welded joints, with exception of pipe D with minimum amount of niobium. Moreover, at the higher content of niobium these precipitates are coarser (see arrows in Figure 1).

The impact toughness of HAZ metal was evaluated on specimens cut out at the region of external weld (Figure 2, specimen EZ) and in the zone of crossing the external and internal welds (Figure 2, specimen CZ). It is known that under conditions of structurally heterogeneous welded joint the determination of tough characteristics of metal and, first of all, HAZ by using impact tests of specimens of standard sizes $(10 \times$ $\times 10 \mathrm{~mm}$ ) is not quite correct, as the obtained values of impact toughness depend to a great extent on specimen disposition and place of a notch. It follows from Figure 2 that in making a notch in HAZ metal of external weld in accordance with GOST 6996-66 the notch section includes only ZCG small area adjacent to the fusion line. The larger share of ZCG is observed in the notch section of specimens cut out from the place of welds crossing. In such specimens the region of reheating of internal weld zone with the most unfavorable structure can also be present.

Results of some tests of specimens with a notch along the fusion line are given in Table 2. The observed large scattering of $K C V$ values at such making of the notch is predetermined by the additional effect of weld shape on impact toughness values. The effect of weld shape on HAZ toughness values is a subject of independent investigations and will be described by us in other publications. Here, we shall only note that the recommended GOST rules of making the notch in HAZ for welds with conditionally good shape factor limit greatly the ZCG share (local zone of brittleness) in the examined section of the impact test specimen.

At the same time, in spite of the observed scattering of test results, the data of Table 2 allow making an adequate conclusion that increase in mass share of niobium in steel for more than $0.05 \%$ leads to decrease in HAZ impact toughness values, in particular in cutting out of specimens in the zone of crossing of internal and external welds. The most noticeable decrease in 
Table 2. Impact toughness of welded joints of pipes investigated $K C V_{-40}, \mathrm{~J} / \mathrm{cm}^{2}$

\begin{tabular}{|c|c|c|c|c|}
\hline \multirow{2}{*}{$\begin{array}{l}\text { Conditional } \\
\text { code of } \\
\text { pipes } \\
\text { (category, } \\
\text { thickness of } \\
\text { BM) }\end{array}$} & \multicolumn{2}{|c|}{ Notch in the weld centre } & \multicolumn{2}{|c|}{ Notch along the fusion line } \\
\hline & $\begin{array}{c}\text { EW } \\
\text { specimens }\end{array}$ & $\begin{array}{c}\mathrm{CW} \\
\text { specimens }\end{array}$ & $\begin{array}{c}\text { EZ } \\
\text { specimens }\end{array}$ & $\begin{array}{c}\mathrm{CZ} \\
\text { specimens }\end{array}$ \\
\hline $\begin{array}{l}\text { A }(X 80, \\
22 \mathrm{~mm})\end{array}$ & $\frac{56-110}{92}$ & $\frac{42-93}{56}$ & $\frac{56-141}{114}$ & $\frac{21-95}{46}$ \\
\hline $\begin{array}{l}\mathrm{C}(\mathrm{X} 80, \\
27.7 \mathrm{~mm})\end{array}$ & $\frac{112-195}{165}$ & $\frac{88-121}{105}$ & $\frac{80-197}{140}$ & $\frac{58-142}{81}$ \\
\hline $\begin{array}{l}\mathrm{D}(\mathrm{X} 65, \\
36 \mathrm{~mm})\end{array}$ & $\frac{185-197}{192}$ & $\frac{152-177}{160}$ & $\frac{290-320}{300}$ & $\frac{100-287}{198}$ \\
\hline \multicolumn{5}{|c|}{$\begin{array}{l}\text { Notes. 1. Numerator indicates minimum and maximum values of } \\
\text { impact toughness, denominator }- \text { mean values of } 6-12 \text { tests. } 2 \text {. } \\
\text { Schemes of cut out of specimens and making a notch are given in } \\
\text { Figure } 2 \text {. }\end{array}$} \\
\hline
\end{tabular}

impact toughness is observed at maximum content of molybdenum, niobium and manganese (pipe A) in steel in the investigated limits, when the least favorable microstructure is formed in ZCG metal.

Investigations after etching of fracture surface of impact test specimens of welded joints with a

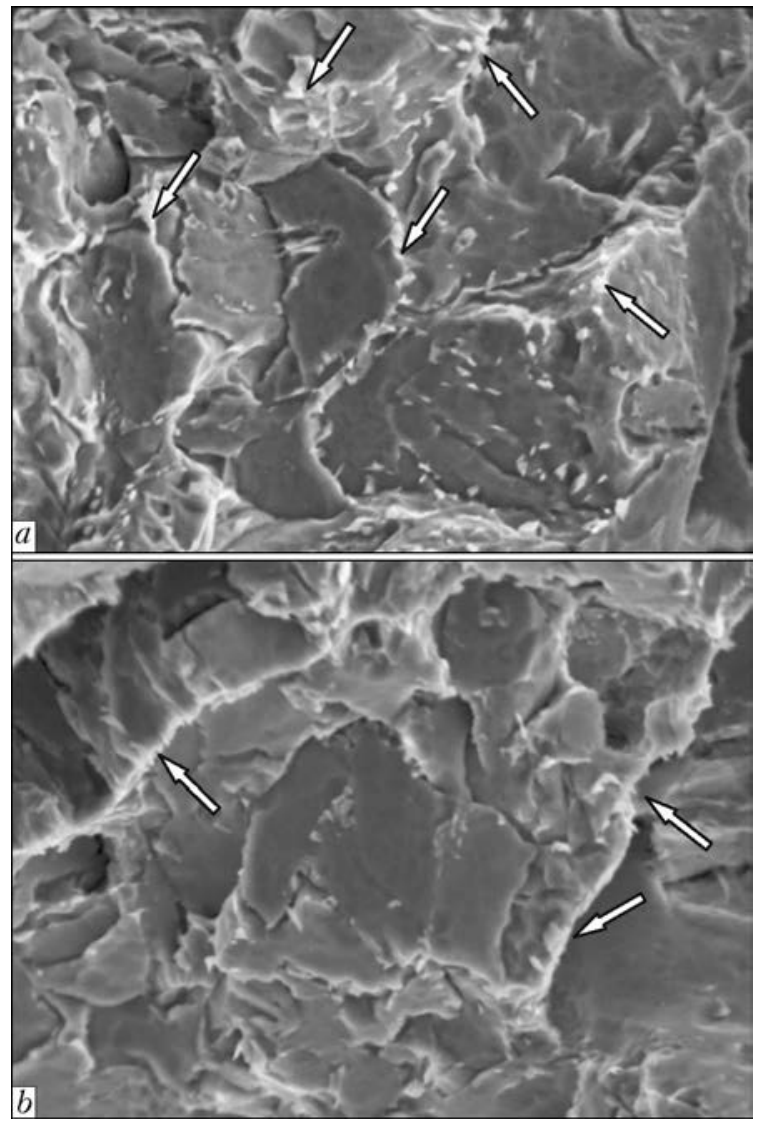

Figure 3. Fractoograms of quasi-brittle regions of fracture of specimens of pipe A $(a)$ and $\mathrm{B}(b)$ with a notch along the fusion line, fractured at temperature $-40{ }^{\circ} \mathrm{C}(\times 2000$, etching in nital) notch along the fusion line confirmed that in weld metal of pipes A and B with high content of niobium and molybdenum at the regions of quasi-brittle fracture along the boundaries of facets the segregations of carbon formations are revealed (they are shown in Figure 3 with light arrows). There are no such formations along the boundaries of the facets in HAZ metal with limited alloying with niobium (for example, pipes $\mathrm{D}$ and $\mathrm{E}$ ).

Similar effect has the increased content of niobium and molybdenum on structural-phase characteristics of the weld metal. In arc welding of large-diameter pipes for main pipelines the niobium is transferred, as is known, into weld metal mainly from the pipe steel. The share of molybdenum in weld metal is determined by its content in steel and welding wire and can be regulated within definite limits by changing of its amount in the latter. Moreover, to increase the tough characteristics the metal of pipe welds is often microalloyed with titanium and boron. Thus, the weld metal represents a rather complexly-alloyed system.

It was found that due to increase in the mass share of niobium up to $0.039-0.047 \%$ and molybdenum up to $0.28-0.35 \%$, because of the higher content of these elements in steel at mass share of manganese of $1.64-1.68 \%$, in weld metal of pipes $\mathrm{A}$ and $\mathrm{B}$ a rather non-homogeneous structure is formed with the formation of constituents of different strength and toughness. The higher content of elements in metal of such welds, actively reducing the temperature of $\gamma \rightarrow \alpha$ transformation ( $\mathrm{Mo}, \mathrm{Mn}, \mathrm{Nb})$, leads also to the formation of regions of the upper bainite, except of the main structure of acicular ferrite ( $75 \%)$ (Figures $4, b$ and 5, $a$ ). MAC-phase is often represented essentially by martensite-austenite complexes with increased content of carbon, but not with products of bainite-martensite transformation (the same as at smaller alloying). Such structural constituent is poorly etched and at examination in the scanning microscope it is revealed as smooth, unstructured light formations (in Figure $5, a, b$ they are shown by light arrows). In addition, the susceptibility to formation of segregations of MAC-phase is distinctly expressed at the boundaries of acicular and grain-boundary polygonal ferrite (Figures 4, $c$ and 5, $a$ ). Due to a limited alloying with titanium and boron, realized by welding wire, the formation of grainboundary polygonal ferrite in weld metal of pipes $\mathrm{A}$ and $\mathrm{B}$ was not suppressed completely ( $\mathrm{Fi}-$ gure $4, a$ ). And though the share of interlayers of hypoeutectic polygonal ferrite is not very high (not more than $10 \%$ even at the periphery regions of weld), the enrichment of their boundaries with 

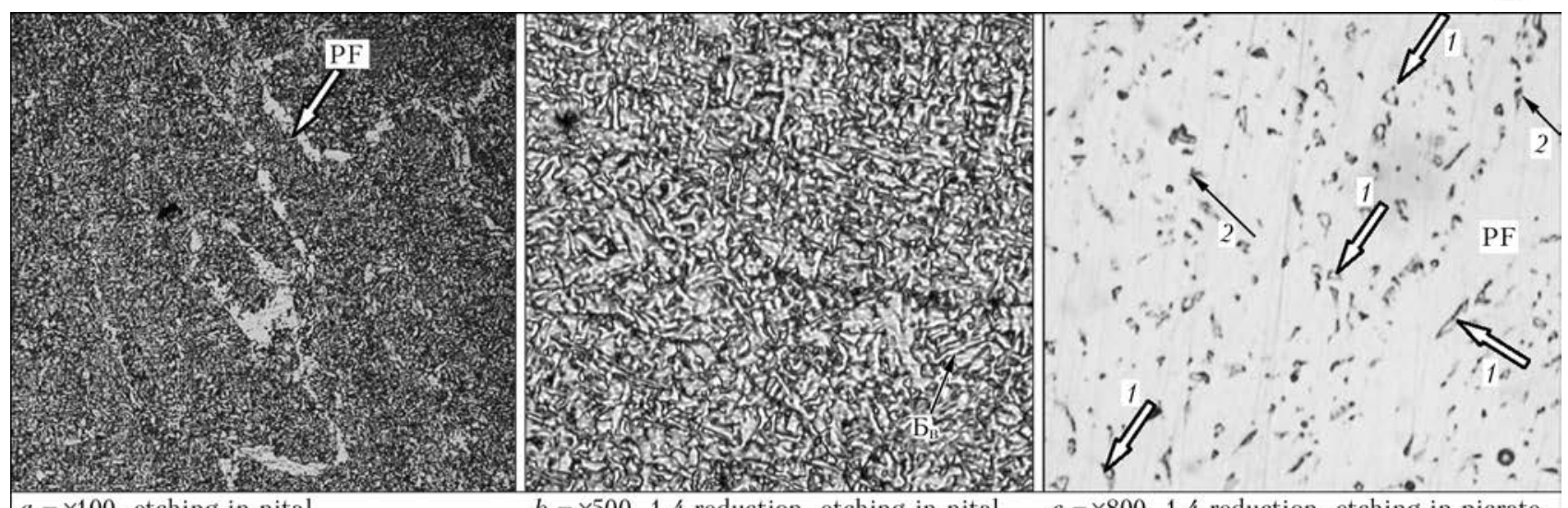

\section{$a-\times 100$, etching in nital}

$b-\times 500,1.4$ reduction, etching in nital
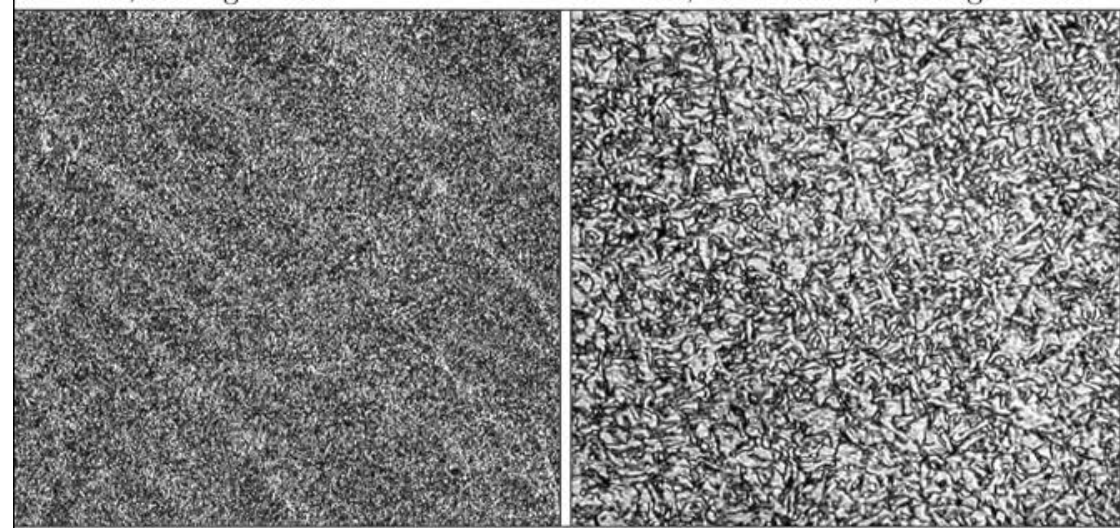

$c-\times 800,1.4$ reduction, etching in picrate

$d-\times 100$, etching in nital

$e-\times 500,1,4$ reduction, etching in nital
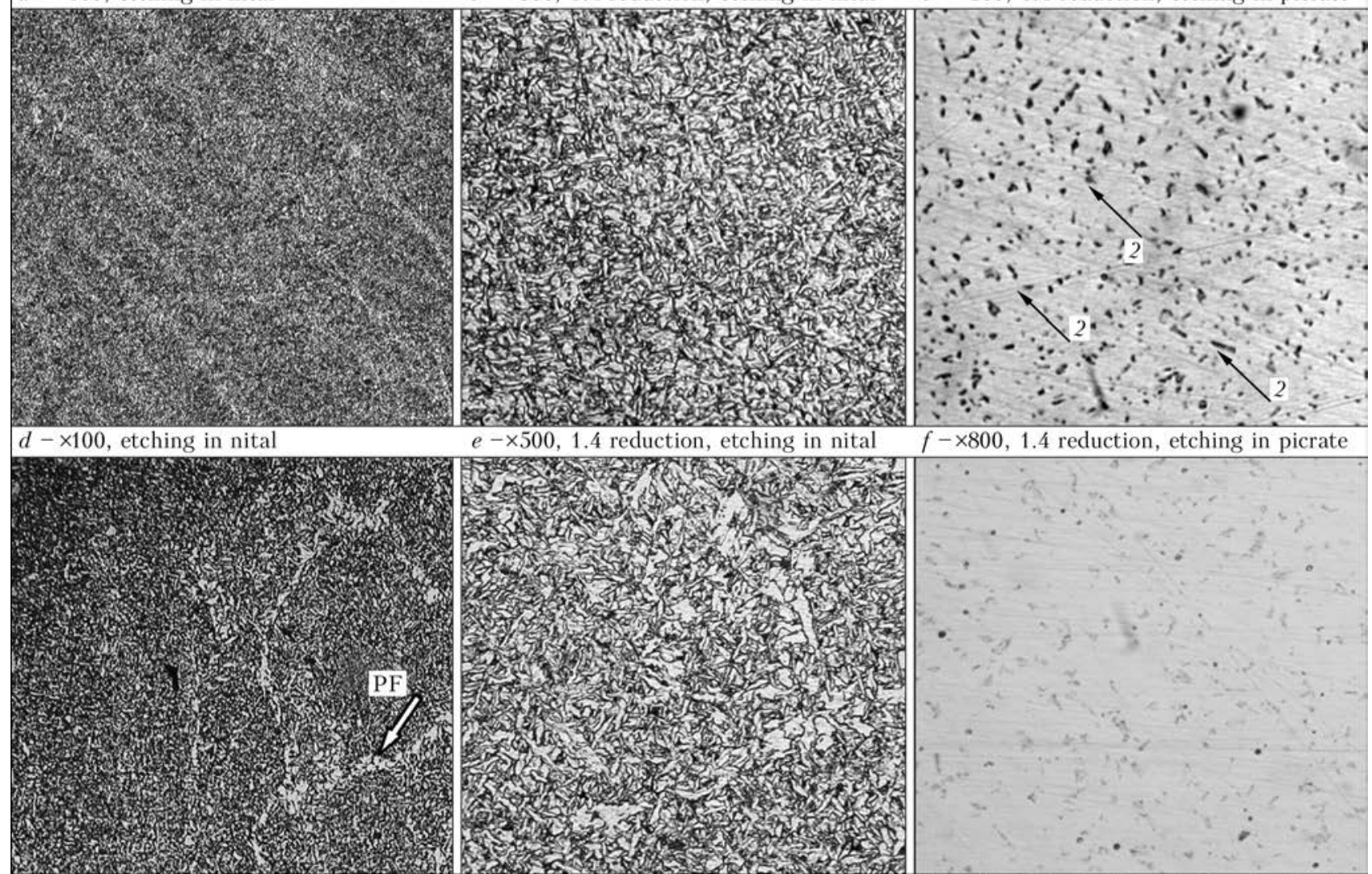

$f-\times 800,1.4$ reduction, etching in picrate

$g-\times 100$, etching in nital

$h-\times 500,1.4$ reduction, etching in nital

Figure 4. Microstructure of metal of external welds with different content of molybdenum and niobium (optic metallography): $a-c-$ pipe A; $d-f-$ pipe $\mathrm{C} ; g-i-$ pipe D; $1-$ martensite-austenite complex; $2-$ MAC-phase

formations of MAC-phase (Figure 4,c), possessing sufficiently high strength, is a negative factor, promoting the fracture initiation. Maximum segregations of carbon phases and structural constituents (MAC-phase, carbides) are observed along the boundaries of crystallites in metal of internal weld at the regions of reheating ( $\mathrm{Fi}^{-}$ gure $6, a, b)$. The developed system of polygonal boundaries, often decorated with MAC-phase precipitates, was also revealed (see Figure $4, b$ ).

The mentioned structural peculiarities cause the higher susceptibility of metal of such welds to the formation of cracks, that is confirmed by the presence of separate relatively large cracks in ferrite interlayers, fringed by MAC-phase, and net of microcracks, localized along the secondary (polygonal) boundaries in one of examined specimens of welded joints of pipe A.

Microstructure of weld metal of pipe $\mathrm{C}$, moderately alloyed with $\mathrm{Nb}(0.022 \%)$, Mo $(0.25 \%)$ and $\mathrm{Mn}$ (about $1.46 \%$ ) is more homogeneous and represented mainly by the dispersed acicular ferrite $(\sim 90 \%)$. The elongated grains of acicular ferrite of 3-4 × 5-15 $\mu \mathrm{m}$ size are disoriented for a large angle (see Figure $4, e$ ). Due to optimum ratio of titanium and boron in weld metal $(0.020$ and $0.003 \%$, respectively) the formation of grain-boundary polygonal ferrite was almost suppressed (only in weld root, $1-3 \%$ of this structural constituent was observed). Negligible struc- 


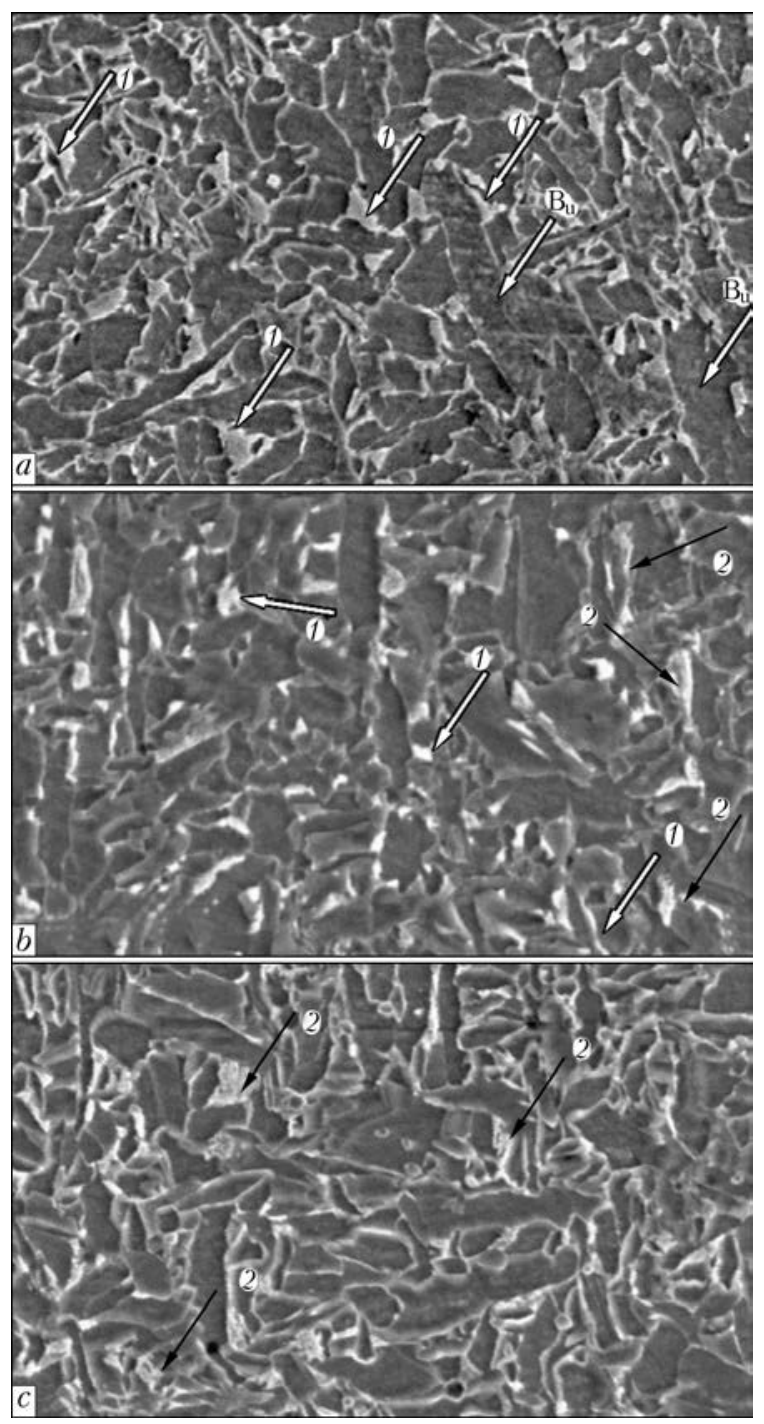

Figure 5. Morphology and topography of MAC-phase in metal of external welds with different content of molybdenum and niobium ( $\times 3000$, scanning microscopy): $a-$ pipe $\mathrm{A} ; b-$ pipe $\mathrm{C} ; c-$ pipe $\mathrm{D} ; 1$ - martensite-austenite complex (light arrows); 2 - MAC-phase (dark arrows)

tural heterogeneity is appeared along the boundaries of crystallites in the form of grains of acicular ferrite of some larger size (Figure $4, d, e$ ). Dispersed MAC-phase, including mainly the products of bainite transformation, is distributed quite uniformly (Figure 4, $f$ ). Clusters of carbon phases and structural constituents along the boundaries of crystallites, including the reheating zone of internal weld, are almost absent (see Figure $6, c, d)$. Polygonal boundaries in such weld are poorly developed (Figure $4, e$ ).

The typical feature of the microstructure of weld metal of pipe D of lower strength (X65) with minimum content of molybdenum $(0.05 \%)$ and niobium $(0.011 \%)$ in weld at mass share of $\mathrm{Mn}$ at the level of $1.70-1.72 \%, \mathrm{Ti}-0.015-$ $0.018 \%$ and $\mathrm{B}-0.0038-0.0040 \%$ is the fact that, in spite of the presence of sufficiently wide layers of grain-boundary polygonal ferrite (6-
$12 \%$, at the periphery - up to $15 \%$ ), except acicular ferrite (about $80 \%$ ), the precipitation of MAC-phase at their boundary, including regions of reheating of internal weld, are absent (Figure 4, $g-i$ ) Grains of the acicular ferrite are close in most cases to equiaxial ones (with shape factor $\chi=1.1-1.5)$. The more elongated $(\chi=$ $=7-8$ ) ferrite grains, present in a small number, are disoriented, therefore, the regions of metal with similar orientation of structures are quite infrequent (see Figure 5, c). Close nature of microstructure is typical of weld metal of pipe E of steel X80, in which the mass share of molybdenum is within the ranges of $0.010-0.13 \%$, and niobium is contained in the amount of $0.021 \%$.

Table 2 gives results of tests of specimens of pipe welded joints with a notch in the weld centre, cut out from the external weld, made finally (EW specimens), and from the zone of crossing the external and internal welds (CW). Scheme of cutting out of specimens and making of notches is given in Figure 2, $a$. As is seen from Table 2, the level of impact toughness of weld metal of test pipes is sufficiently high in general. This is due, in the first turn, to application of advanced welding consumables: agglomerated aluminate flux of low basicity and welding wires with Mo, $\mathrm{Ni}, \mathrm{Ti}$ and B. Optimum combination of these elements provides the preferable formation of acicular ferrite structure with high tough characteristics in weld metal (see Table 2, pipes C, D). At the same time, the excessive alloying of weld of pipe A with molybdenum $(0.35 \%)$ and $\mathrm{Nb}(0.039 \%)$, accompanied, as was noted, by the appearance in structure of regions of upper bainite and segregations of carbon phases along the boundaries of crystallites, decreases the values of impact toughness (see Table 2, pipe A, EW specimens).

The higher decrease in tough characteristics is noted in the case when the test section of impact test specimen of pipe A with increased content of $\mathrm{Mo}$ and $\mathrm{Nb}$ includes the region of metal of internal weld with unfavorable structure, subjected to reheating in welding of external weld (Table 2, CW specimen). For welds with lower share of molybdenum and niobium (Table 2, pipes $\mathrm{C}$ and $\mathrm{D}$ ) the decrease in impact toughness at testing of these specimens is appeared to a much less extent.

Fractographic investigations of fracture surface of impact test specimens with a notch along the axis of weld showed that the weld metal at increased content of $\mathrm{Mo}, \mathrm{Nb}$ and $\mathrm{Mn}$ (pipe A) even at temperature $-10{ }^{\circ} \mathrm{C}$ is fractured mainly by a quasi-brittle mechanism, here, the elongated smooth (quasi-brittle) regions, corresponding to 


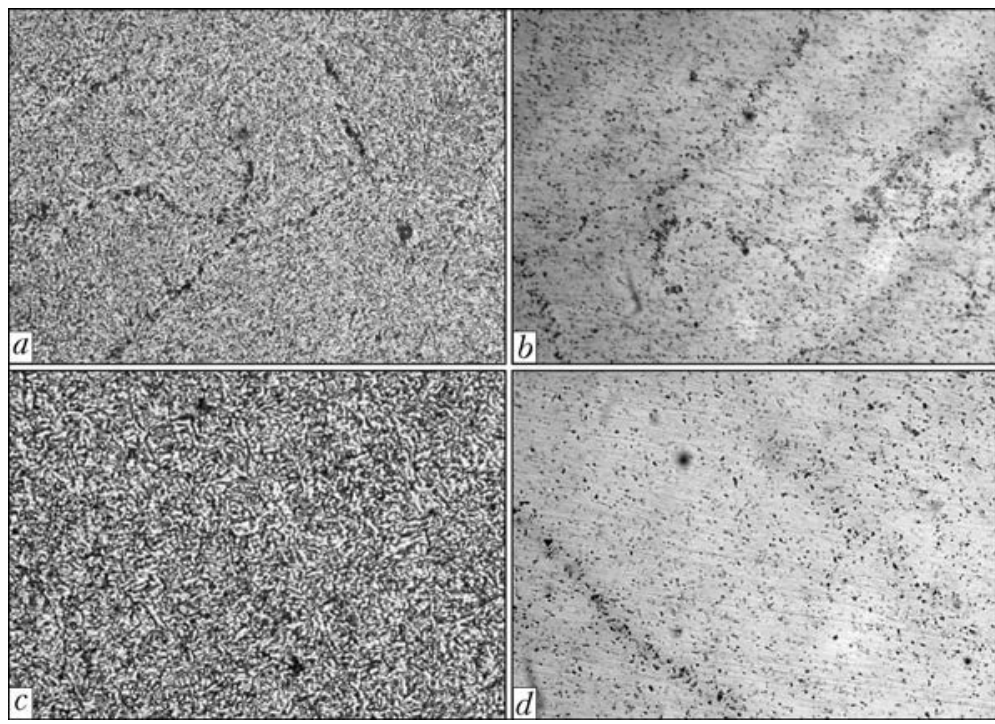

Figure 6. Typical microstructure of metal of internal weld in the zone of reheating of welded joint of pipe A $(a, b)$ and pipe $C(c, d)$ of steel with different content of niobium and molybdenum

interlayers of hypoeutectic grain-boundary polygonal ferrite with boundaries enriched with carbon precipitates, revealed earlier in study of results of metallographic examinations, were observed at small tough areas of the fracture surface. In case of limited alloying of weld metal (pipes $\mathrm{C}$ and $\mathrm{D}$ ) the share of areas of tough fracture at $-40{ }^{\circ} \mathrm{C}$ is within the limits from 10 up to $50 \%$. In this case the tough regions are located under the notch of impact test specimens, and their length is not less than $2 \mathrm{~mm}$, that predetermines the high values of the impact toughness.

Thus, the results of carried out investigations confirmed the negative effect of increased content of niobium (in steel of more than $0.05 \%$ and more than $0.03 \%$ in weld), which is intensified in the presence of molybdenum, on structural characteristics of weld metal and HAZ. Taking into account the susceptibility of niobium, similarly to sulfur, to segregation, the additional alloying with molybdenum, reducing the temperature of transformation, leads to the formation of unfavorable structural constituents and phases, as well as to their clustering along the grain boundaries in metal of the welded joints. At such amount of niobium and molybdenum in ZCG metal the packets of bainite structure are formed with coarser carbon phase of the lath morphology, and clusters of MAC-phase and carbides are precipitated along the boundaries of former austenite grains, in particular in the reheating zones.

In weld metal containing the mass share of Mo of more than $0.3 \%$ and $\mathrm{Nb}$ of more than $0.03 \%$, at $\mathrm{Mn}$ on the level of $1.6 \%$ and higher, the regions of the upper bainite are formed, length of polygonal boundaries and amount of MAC-phase precipitates along the grain boundaries are increased, and also the share of martensite in the composition of this structural constituent is increased. These structural changes of weld metal, as also in HAZ metal, are appeared to a larger extent in the reheating zones.

By this reason, to provide the high impact toughness and crack resistance of metal of joints in welding of pipes of high-strength microalloyed steel it is necessary to limit the content of niobium $(\leq 0.05 \%)$ and molybdenum $(\leq 0.20 \%)$, as well as to apply the welding consumables, providing the mass share of molybdenum in weld of not more than $0.30 \%$.

1. Morozov, Yu.D., Efron, L.I. (2006) Steels for pipes of main pipelines: State-of-the-art and tendencies of developments. Metallurg, 5, 54-56.

2. Efron, L.I., Nastich, S.Yu. (2006) State of the manufacturing of sheet products and coiled stock for spirally welded pipes of strength category up to X100. «Chermetinformatsiya». Bull. Chyorn. Metallurgiya, 11, 68-81.

3. Morozov, Yu.D., Matrosov, M.Yu., Nastich, S.Yu. et al. (2008) High-strength pipe steels of new generation with ferrite-bainite structure. Metallurg, 8, 39-42.

4. De Moor, E., Gibbs, P.J., Speer, J.G. et al. (2010) Strategies for third-generation advanced highstrength steel development. Iron and Steel Techn., 11, 133-144.

5. Hamada, M., Fukada, Y., Komizo, Y. (1995) Microstructure and precipitation behavior in heat affected zone of $\mathrm{C}-\mathrm{Mn}$ microalloyed steel containing $\mathrm{Nb}, \mathrm{V}$ and Ti. ISIJ Int., 35(10), 1196-1201.

6. Graf, M., Niederhoff, K. (1990) Toughness behavior of the heat-affected zone (HAZ) in submerged-arc welded large-diameter pipe. In: Proc. of Pipeline Technology Conf. (Oostende, Belgium, 15-18 Oct. 1990), 131-139.

7. Li, Y., Crowther, D.N., Green, M.J.W. et al. (2001) The effect of vanadium and niobium on the properties and microstructure of the intercritically reheated coarse grained heat affected zone in low carbon microalloyed steels. ISIJ Int., 41(1), 46-55.

8. Rybakov, A.A. (2009) Current state of manufacturing of large diameter pipes for main pipelines. In: Proc. of Sci.-Techn. Seminar on Service Reliability Control of Pipeline Transportation Systems (Kiev, 10-11 June 2009), 48-52. 